https://helda.helsinki.fi

Surface coverage dependent mechanisms for the absorption and desorption of hydrogen from the $\mathrm{W}(110)$ and $\mathrm{W}(100)$

surfaces : a density functional theory investigation

\title{
Ajmalghan, Muthali
}

2019-10

Ajmalghan , M , Piazza , Z , Hodille , E \& Ferro , Y 2019 , ' Surface coverage dependent mechanisms for the absorption and desorption of hydrogen from the $\mathrm{W}(110)$ and $\mathrm{W}(100)$ surfaces : a density functional theory investigation ' , Nuclear Fusion, vol. 59 , no. 10 , 106022 . https://doi.org/10.1088/1741-4326/ab33e7

http://hdl.handle.net/10138/305498

https://doi.org/10.1088/1741-4326/ab33e7

acceptedVersion

Downloaded from Helda, University of Helsinki institutional repository.

This is an electronic reprint of the original article.

This reprint may differ from the original in pagination and typographic detail.

Please cite the original version. 


\section{Surface coverage dependent mechanisms for the absorption and desorption of hydrogen from the W(110) and W(100) surfaces: a DFT investigation.}

To cite this article before publication: Muthali Ajmalghan et al 2019 Nucl. Fusion in press https://doi.org/10.1088/1741-4326/ab33e7

\section{Manuscript version: Accepted Manuscript}

Accepted Manuscript is "the version of the article accepted for publication including all changes made as a result of the peer review process, and which may also include the addition to the article by IOP Publishing of a header, an article ID, a cover sheet and/or an 'Accepted

Manuscript' watermark, but excluding any other editing, typesetting or other changes made by IOP Publishing and/or its licensors"

This Accepted Manuscript is @ E EURATOM 2019.

During the embargo period (the 12 month period from the publication of the Version of Record of this article), the Accepted Manuscript is fully protected by copyright and cannot be reused or reposted elsewhere.

As the Version of Record of this article is going to be / has been published on a subscription basis, this Accepted Manuscript is available for reuse under a CC BY-NC-ND 3.0 licence after the 12 month embargo period.

After the embargo period, everyone is permitted to use copy and redistribute this article for non-commercial purposes only, provided that they adhere to all the terms of the licence https://creativecommons.org/licences/by-nc-nd/3.0

Although reasonable endeavours have been taken to obtain all necessary permissions from third parties to include their copyrighted content within this article, their full citation and copyright line may not be present in this Accepted Manuscript version. Before using any content from this article, please refer to the Version of Record on IOPscience once published for full citation and copyright details, as permissions will likely be required. All third party content is fully copyright protected, unless specifically stated otherwise in the figure caption in the Version of Record.

View the article online for updates and enhancements. 


\title{
Surface coverage dependent mechanisms for the absorption and desorption of hydrogen from the W(110) and W(100) surfaces: a DFT investigation.
}

\author{
M. Ajmaghan ${ }^{1}$, Z. A. Piazza ${ }^{1}$, E. A. Hodille ${ }^{2}$, and Y. Ferro ${ }^{1, *}$ \\ ${ }^{1}$ Aix Marseille Univ, CNRS, PIIM, Marseille, France \\ ${ }^{2}$ Department of Physics, P.O. Box 43, FI-00014 University of Helsinki, Finland
}

\begin{abstract}
Herein we investigate absorption and desorption of hydrogen in the sub-surface of tungsten via Density Functional Theory. Both the near-surface diffusion and recombination of a bulk hydrogen atom with a hydrogen atom adsorbed upon the W(110) and W(100) surfaces are investigated at various surface adsorption coverage ratios. This study intends to model the desorption processes occurring during Thermal-Desorption Spectroscopy experiments and the absorption of hydrogen during gaseous or low energy atomic exposure. Since the diffusion and recombination processes are expected to change as the hydrogen coverage of the surface varies, different coverage ratios were investigated on both surfaces. We found that at saturation coverage of hydrogen on both surfaces, the activation barriers for the recombination of molecular hydrogen are below $0.8 \mathrm{eV}$. On the contrary, below saturation, the activation barriers for recombination rise to $1.35 \mathrm{eV}$ and $1.51 \mathrm{eV}$ depending on the coverage and on the orientation of the surface. Regarding the absorption of atomic hydrogen from the surface into the bulk, the activation barrier raises from less than $1.0 \mathrm{eV}$ at saturation to around $1.7 \mathrm{eV}$ below saturation on both surfaces. These results indicate that surface mechanisms certainly play a significant role in the kinetics of desorption of hydrogen from tungsten; it is also expected that surface mechanisms affect the total amount on hydrogen absorbed in tungsten during implantation.
\end{abstract}

\section{Corresponding author: yves.ferro@univ-amu.fr}




\section{Introduction}

One of the main challenges of modern society is to find a reliable source of energy other than fossil fuel. Nuclear fusion emerges as a possible, clean and efficient way to produce energy. However, one key aspect of feasible fusion power reactors is the choice of suitable plasma facing materials (PFM). Tungsten (W) has a high melting point, low tritium solubility, high thermal conductivity, and a high sputtering threshold [1-4]; it constitutes the divertor plates of JET [5,6], WEST [7] and future ITER tokamaks [8,9]. However, during interactions between the plasma and the wall, $\mathrm{W}$ materials will be irradiated by a high flux of hydrogen isotopes $\left(\sim 10^{24} \mathrm{~m}^{-2} \mathrm{~s}^{-1}\right)$. These hydrogen isotopes can enter the material and be trapped in it, which is one of the main concerns from the safety point of view; the amount of tritium is regulation-limited inside the vacuum vessel. The retention of hydrogen isotopes is also a source of concern for operating the machine, since the recycling flux of molecules/atoms/ions from the wall to the plasma can affect the plasma operations $[10,11]$. In order to better understand both these safety and operating issues, many theoretical and experimental modeling activities are led in laboratories; the main objective is to achieve a full understanding of hydrogen-tungsten interactions and to establish reliable models with predictable capabilities describing the behavior of hydrogen in tungsten depending on the experimental conditions.

From the experimental point of view, much effort has been put on Thermal Desorption Spectroscopy (TDS), also called Temperature Programmed Desorption (TPD) [12-15], and on ion beam analysis, such as Nuclear Reaction Analysis (NRA) [16-19] or Second Ions Mass Spectrometry (SIMS) [20]. Elastic Recoil Detection Analysis (ERDA) [21], Low Energy Ion Scattering (LEIS) and Direct Recoil Spectroscopy (DRS) [22-24] are also used, mostly to gain information on the surface properties. TDS can access global information related to the binding state of hydrogen in the bulk and on the surface, while ion beam analysis accesses local 
information on the concentration of hydrogen isotopes at depth up to a few micrometers (NRA, SIMS).

From the theoretical point of view, calculations and simulations have been carried out from the atomistic scales using Density Functional Theory (DFT) [24-38] and Molecular Dynamics (MD) [39-43], to the macroscopic scale using Kinetic Monte Carlo (KMC) [44-47] and Macroscopic Rate Equations (MRE) [15,48-60]. Combining both these approaches results in the commonly called multi-scale approach, in which KMC [44,45] and MRE models are parametrized with available DFT data. But in most of the published KMC or MRE models, due to the lack of available DFT data, the surface processes for hydrogen are either neglected $[49,51-56,59]$ or considered in a simplified way with models making use of the recombination coefficient for hydrogen $[15,48,58,60]$. An accurate experimental value of the recombination coefficient is nevertheless unestablished due to large uncertainty from available measurements [61].

There is thus a real need to consider surface effects in great detail, including the recombination/adsorption of hydrogen from the various tungsten surfaces; an experimental study by Markelj et al. [62] show that the penetration of low energy atom in tungsten is mostly limited by surface processes. Furthermore, a study by 't Hoen et al [63] seems to suggest that surface processes are also limiting the absorption of $\mathrm{D}$ even for $5 \mathrm{eV} / \mathrm{D}$ ions. Such low energies can be reached in the detached regime of the divertor plasma in tokamaks [64].

Consequently, surface processes have been recently included in MRE models $[50,57,65]$. These approaches are based on a kinetic model from Pick et al. $[66,67]$ who considers three distinct regions in the system; they are the vacuum (v), the (sub-)surface (s) and the bulk (b). The time evolution of the concentration of hydrogen is solved, considering the flux of hydrogen exchanged between each of these regions, which corresponds to the processes of desorption $(\mathrm{s} \rightarrow \mathrm{v})$, absorption $(\mathrm{s} \rightarrow \mathrm{b})$, and surfacing $(\mathrm{b} \rightarrow \mathrm{s})$. As a consequence, the input data for the surface 
model in MRE codes are the activation energies of each of these processes. The activation energies for desorption at the surface are expected to be highly dependent on the surface coverage, as is suggested by experimental studies [62,68-71]. Some previous theoretical studies attempted to determine part of the absorption and surfacing energies on the $\mathrm{W}(110)$ and $\mathrm{W}(100)$ bare surfaces $[27,28,30,38]$; however, to our knowledge, the dependence of these mechanisms with the hydrogen coverage has never been computationally investigated for hydrogen in tungsten.

This missing knowledge motivates the objectives of the present paper to establish surfacecoverage dependent mechanisms and energetics for 1) the diffusion of hydrogen in the subsurface region, 2) the recombination into molecular hydrogen on top of the tungsten surface, and 3) the absorption of hydrogen into the bulk. This work consequently aims at providing relevant activation energies and at determining their dependence with respect to the coverage in hydrogen of the surface.

This paper is organized as follows: after giving the details of the calculations in section 2, we first provide the results obtained at saturation of hydrogen on the W(110) and W(100) surfaces. The activation barriers and diffusion paths are provided for a hydrogen atom diffusing from the bulk to the surface and reversely, and the recombination processes occurring at the surface are examined and characterized by their activation energies in section 3 . In section 4 , the W(110) and $\mathrm{W}(100)$ surfaces are considered below saturation, at coverage 0.75 and 0.5 , respectively, in order to mimic the surface depletion under heating up of the sample during TPD experiments. In section 5, results from simulations are discussed and compared to the ones available in the literature before a conclusion is given in section 6 . 


\section{Computational Methods}

\section{1 - Electronic structure calculations}

All the DFT calculations were performed with Quantum Espresso code [72] using the PBE [73] exchange-correlation functional and corresponding Vanderbilt ultra-soft scalar-relativistic pseudo-potentials (USPP) [74] for hydrogen and tungsten. We used energy cutoffs of 40 Ry and 320 Ry for the wave function and electron density, respectively. A Marzari-Vanderbilt (MV) smearing [75] scheme with a Gaussian broadening of $5 \times 10^{-2} R y$ and a k-point sampling of $9 \times 9 \times 1$ for $\mathrm{W}(110)$ and $7 \times 7 \times 1$ for $\mathrm{W}(100)$ were shown to be converged. In order to have an accurate description of the interaction between hydrogen atoms and the tungsten surfaces, we considered 14 valence and semi-core electrons for tungsten atoms as in our recent publication [24,25]. The convergence threshold for the self-consistency for the electronic calculations was chosen at $10^{-7}$ Ry and was extended to $10^{-9}$ Ry for phonon calculations. The geometry of the atoms in the unit-cell were geometrically relaxed to a force convergence threshold of $10^{-5}$ Ry. $\AA^{-1}$. This threshold was extended to $10^{-7}$ Ry. $\AA^{-1}$ when phonon calculations were performed. Phonons were calculated via Density Functional Perturbation Theory DFPT [76] to provide zero-point energy (ZPE) corrections. The ZPE correct energies are indicated with ZPE in superscript as $E^{Z P E}$ in the reminder of the text. It should be noted that the ZPE corrections were only applied for $\mathrm{H}$ atoms, not for $\mathrm{W}$ atoms. The validity of this approximation was already discussed in a previous paper [25].

\section{2 - Model of the W(100) and W(110) surfaces}

In this work, we used six-layer slabs to model the W(100) and W(110) surfaces with adsorbed hydrogen. Each configuration discussed in the paper was geometrically optimized to its local minimum. All of the atoms were relaxed during the geometry optimization procedure except the fifth and sixth layers (the bottom two layers) which were held fixed to the bulk geometry. 
This model was already shown to provide the depth necessary for well converged surface properties [24]. The surfaces we used are a rhombus working-cell for the W(110) surface and a $2 \times 2$ working cell for the W(100) surface; both surface models are displayed in Figure 1 . The primitive vector of the bulk unit cell are consistent with our previous DFT studies at $a_{\text {bulk }}=$ $3.187 \AA[25]$. The rhombohedral slab model of the W(110) surface was built using a monoclinic Bravais lattice with unit-vectors of $\mathbf{a}=\mathbf{b}=\sqrt{3} a_{b u l k}$ and $\mathbf{c}=31.268 \AA$. The $2 \times 2$ surface model of the W(100) surface was built with $\mathbf{a}=\mathbf{b}=2 a_{\text {bulk }}$ and $\mathbf{c}=28.068 \AA$. The surface area of each working-cell is $30.471 \AA^{2}$ and $40.628 \AA^{2}$ for the W(110) and W(100) models, respectively. Both models include a $20.0 \AA$ vacuum in the c-direction.

(a)

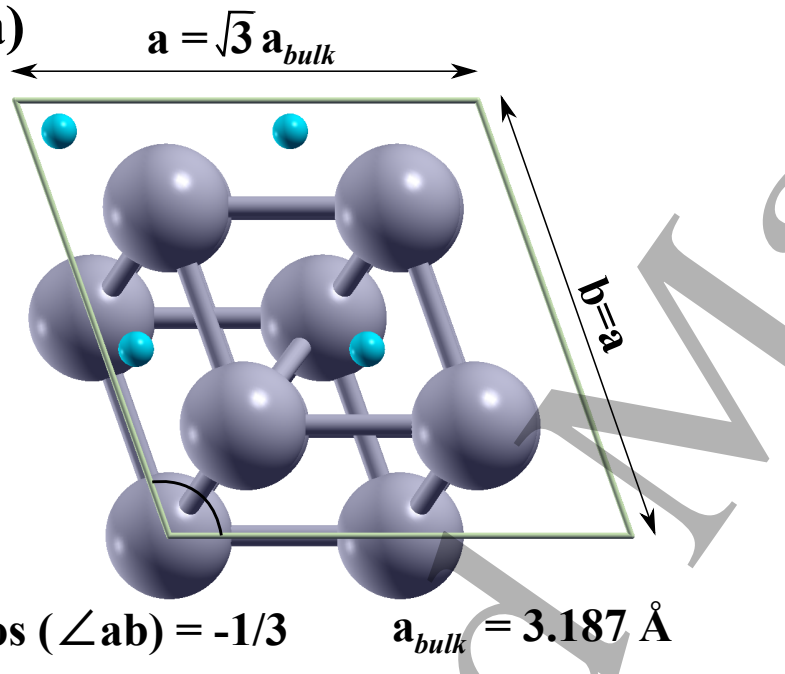

$\mathrm{W}(110) \quad \Theta=1.0$

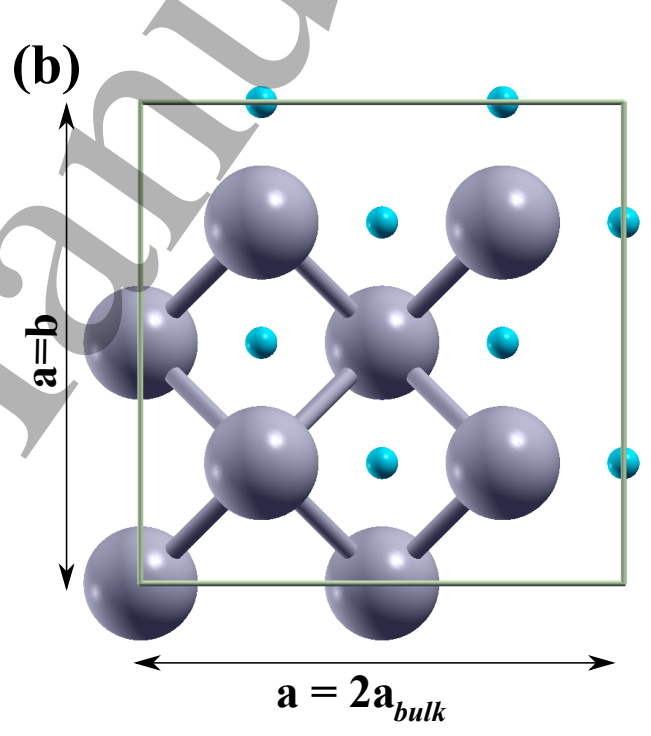

$\mathrm{W}(100) \quad \Theta=2.0$

Figure 1: Definition of the working cell used to model the (a) W(110) and (b) W(100) surfaces. Both surfaces are pictured here with one monolayer of hydrogen (blue atoms represent the surface hydrogens), corresponding to coverage $\Theta=1.0$ on $\mathrm{W}$ (110) and coverage $\Theta=1.0$ on $\mathrm{W}(100)$.

\section{3-Calculation of hydrogen-tungsten interactions}

In the following, we consider the tungsten surfaces at different macroscopic coverages $\Theta$ in hydrogen, with $\Theta=n_{H}$ adsorbed $/ n_{W \text { surface }}$. An extra hydrogen atom is added below the surface, whose solution energy $\Delta E_{\text {sol }}$ according to equation (1) is: 


$$
\Delta E_{\text {sol }}=E_{\Theta+H_{\text {bulk }}}-\left(E_{W_{\Theta}}+\frac{1}{2} E_{H_{2}}\right)
$$

The extra-hydrogen atom diffuses and reaches the surface. Configurations where the extra hydrogen atom resides on the surface correspond to a local coverage of $\Theta^{\prime \prime}=\Theta+1 / n_{\text {Wsurface }}$ in the unit-cell, which is $\Theta^{\prime \prime}=\Theta+0.25$ in the present study (since both the $\mathrm{W}(100)$ and $\mathrm{W}(110)$ are comprised of 4 surface tungsten atoms in the unit-cell). Two hydrogen atoms on the surface finally recombine and $\mathrm{H}_{2}$ molecule is formed leaving the surface with a local coverage $\Theta^{\prime}=\Theta-1 / n_{\text {Wsurface }}\left(\Theta^{\prime}=\Theta-0.25\right)$. This led us to define an embedding energy $\Delta E_{\text {emb }}$ for the $\mathrm{H}_{2}$ molecule, the zero energy or reference is defined when the $\mathrm{H}_{2}$ molecule is away from the surface and the surface of the working-cell is at coverage $\Theta^{\prime}$ :

$$
\Delta E_{\text {emb }}=E_{\Theta+H_{\text {bulk }}}-\left(E_{W_{\Theta},}+E_{H_{2}}\right)
$$

Minimum energy paths for the relevant processes are calculated when necessary using the Nudge Elastic Band (NEB) technique [77,78], which yields the activation energy $\left(E^{\ddagger}\right)$ for diffusion and recombination at the surface. The NEB calculations were considered converged once the norm of the forces orthogonal to the path are less than $5 \times 10^{-5} \mathrm{eV} . \AA^{-1}$. Pathways of the overall processes are constructed via a series of NEB paths. Each corresponds to the connection of two minima passing through a single transition state. All the paths were further concatenated yielding the total minimum energy path leading up from the bulk to the top of the surface where hydrogen recombination occurs.

\section{Hydrogen desorption from the saturated W(110) and W(100) surfaces}

\section{1 - Stable interstitial positions}

Previous DFT [24] and experimental [68,69,22-24] studies determined the saturation limit of hydrogen on tungsten; it is reached at coverage $\Theta=1.0$ on the W(110) surface, and at coverage $\Theta=2.0$ on the $\mathrm{W}(100)$ surface. As a consequence, we first investigated coverages $\Theta=1.0$ and $\Theta=2,0$ in their most stable configurations on the W (110) and W (100) surfaces, respectively; 
top view representations are given in Figure 1.

The solution energy and recombination properties of hydrogen were examined by placing an extra hydrogen atom below the surface at an interstitial site of tetrahedral $\left(T_{d}\right)$ symmetry. $A$ diffusion path was further constructed; it connects neighboring $T_{d}$ site from the surface to the bottom of the model. $T_{d}$ sites are labeled staring from $Z_{1}$ at the surface to $Z_{6}$ or $Z_{7}$ deeper in the sub-surface. As each configuration was geometrically relaxed, the distance between two neighboring $\mathrm{T}_{\mathrm{d}}$ sites varies within $\pm 0.02 \AA$ but remains close to its value in the bulk at $1.19 \AA$. More details on the calculated path are given in the supplementary information.

3.2 - Hydrogen desorption/absorption from the W(110) saturated surface (coverage $\Theta=1.0)$

Table 1 shows the absorption $\Delta E_{e m b}$ and solution $\Delta E_{\text {sol }}$ energies of a hydrogen atom occupying the $Z_{1}-Z_{7} T_{d}$ sites below the hydrogen-saturated unit-cell at coverage $\Theta=1.0 . \mathrm{ZPE}$ corrected energies are also displayed. The ZPE correction being different for hydrogen in the gas phase and in tungsten, its main effect is to offset embedding and solution energy values by around 0.1 to $0.2 \mathrm{eV}$. The depth at which the hydrogen atom resides is $\mathrm{d}_{\mathrm{H}-\mathrm{surf}}$. The reference $\mathrm{d}_{\mathrm{H}-}$ surf $=0$ is defined by the tungsten atom with maximum height; it is negative for hydrogen below the surface, positive for hydrogen above.

On top of the W(110) surface, two distinct configurations are observed; one of them corresponds to the most stable configuration for coverage $\Theta^{\prime \prime}=1.25$ and is referred to as $\mathrm{S}_{0}$, the other corresponds to an intermediate state toward recombination and is referred as $\mathrm{S}_{1}$. Above the surface in $\mathrm{S}_{\text {ref, }} \mathrm{a} \mathrm{H}_{2}$ molecule lies about $6 \AA$ above the tungsten surface. 
Table 1: Embedding and solution energies as defined in equation 1 and 2 . The $Z_{j}$ refer to the location of the interstitial sites below the W(110) surface. The distance from $\mathrm{Zj}$ to the surface is given by $\mathrm{d}_{\mathrm{H}-\text { surf. }}$

\begin{tabular}{cccccc}
\hline \hline $\mathrm{Z}_{\mathrm{j}}$ & $\Delta E_{\text {emb }}$ & $\Delta E_{\text {sol }}$ & $\Delta E_{\text {emb }}^{Z P E}$ & $\Delta E_{\text {sol }}^{Z P E}$ & $\mathrm{~d}_{\mathrm{H}-\text { surf }}(\AA)$ \\
\hline$S_{\text {ref }}$ & 0 & 0.63 & 0.04 & 0.63 & +6.09 \\
$\mathrm{~S}_{1}$ & -0.51 & 0.12 & -0.37 & 0.22 & +1.80 \\
$\mathrm{~S}_{0}$ & -0.69 & -0.05 & -0.55 & 0.04 & +1.32 \\
$\mathrm{Z}_{1}$ & 0.14 & 0.78 & 0.29 & 0.88 & $-0.54)$ \\
$\mathrm{Z}_{2}$ & 0.22 & 0.86 & 0.39 & 0.98 & -1.17 \\
$\mathrm{Z}_{3}$ & 0.33 & 0.97 & 0.48 & 1.08 & -1.68 \\
$\mathrm{Z}_{4}$ & 0.27 & 0.91 & 0.44 & 1.03 & -2.86 \\
$\mathrm{Z}_{5}$ & 0.23 & 0.87 & 0.40 & 0.99 & -3.37 \\
$\mathrm{Z}_{6}$ & 0.20 & 0.84 & 0.38 & 0.97 & -3.92 \\
$\mathrm{Z}_{7}$ & 0.22 & 0.85 & 0.39 & 0.98 & -5.08 \\
\hline \hline & & & & & \\
\hline
\end{tabular}

The diffusion path of a hydrogen atom moving from the bulk to the surface is the minimum energy path (MEP) joining the nearest neighbors $Z_{j}$ displayed in Figure 2 and Table 1 . The $Z_{j}$ and $\mathrm{Z}_{\mathrm{j}-1}$ configurations were used as the initial and final positions of individual NEB calculations. The full diffusion path is shown in Figure 2. Of course, some other paths could have been selected. A hydrogen atom is likely to take lateral steps on its way towards the surface. Nevertheless, due to the absence of significant surface reconstruction on the W(110) surface, the energy profile would not be significantly affected by varied lateral moves in the sub-surface or bulk regions. We consequently choose the shortest path possible leading from the bulk to the surface, under the constraint that the system passes through the minimal energy surface states.

Figure 2a presents the complete energy profile of a hydrogen atom diffusing across the W(110) surface at coverage $\Theta=1.0$. The abscissa corresponds to the reaction co-ordinate $\left(\mathrm{Z}_{\mathrm{j}}\right)$ and the 
ordinate to the embedding energy $\Delta E_{\text {emb }}$ defined in eq. (2). All the activation energies $E^{t}$ are reported in Table 2 in both directions: toward the surface $E_{\rightarrow \text { surf }}^{\ddagger}$ and toward the bulk $E_{\rightarrow \text { bulk }}^{\ddagger}$. These energies were taken from the NEB calculations and are consequently not ZPE corrected. Figure $2 \mathbf{b}$ displays each of the $Z_{j}$ positions in correspondence with the minima shown in Figure $2 a$.

Table 2: Activation energies toward the surface $E_{\rightarrow \text { surf }}^{\ddagger}$ and toward the bulk $E_{\rightarrow \text { bulk }}^{\ddagger}$ between $Z_{j}$ and $Z_{j-1}$ for the $W(110)$ surface at coverage $\Theta=1.0$.

\begin{tabular}{ccc}
\hline \hline $\mathrm{Z}_{\mathrm{j}}-\mathrm{Z}_{\mathrm{j}+1}$ & $E_{\rightarrow \text { surf }}^{\ddagger}$ & $E_{\rightarrow \text { bulk }}^{\ddagger}$ \\
\hline $\mathrm{S}_{\mathrm{ref}}-\mathrm{S}_{1}$ & 0.62 & 0.11 \\
$\mathrm{~S}_{1}-\mathrm{S}_{0}$ & 0.48 & 0.31 \\
$\mathrm{~S}_{0}-\mathrm{Z}_{1}$ & 0.07 & 0.90 \\
$\mathrm{Z}_{1}-\mathrm{Z}_{2}$ & 0.11 & 0.18 \\
$\mathrm{Z}_{2}-\mathrm{Z}_{3}$ & 0.06 & 0.17 \\
$\mathrm{Z}_{3}-\mathrm{Z}_{4}$ & 0.33 & 0.27 \\
$\mathrm{Z}_{4}-\mathrm{Z}_{5}$ & 0.20 & 0.16 \\
$\mathrm{Z}_{5}-\mathrm{Z}_{6}$ & 0.21 & 0.19 \\
$\mathrm{Z}_{6}-\mathrm{Z}_{7}$ & 0.21 & 0.20 \\
\hline \hline
\end{tabular}




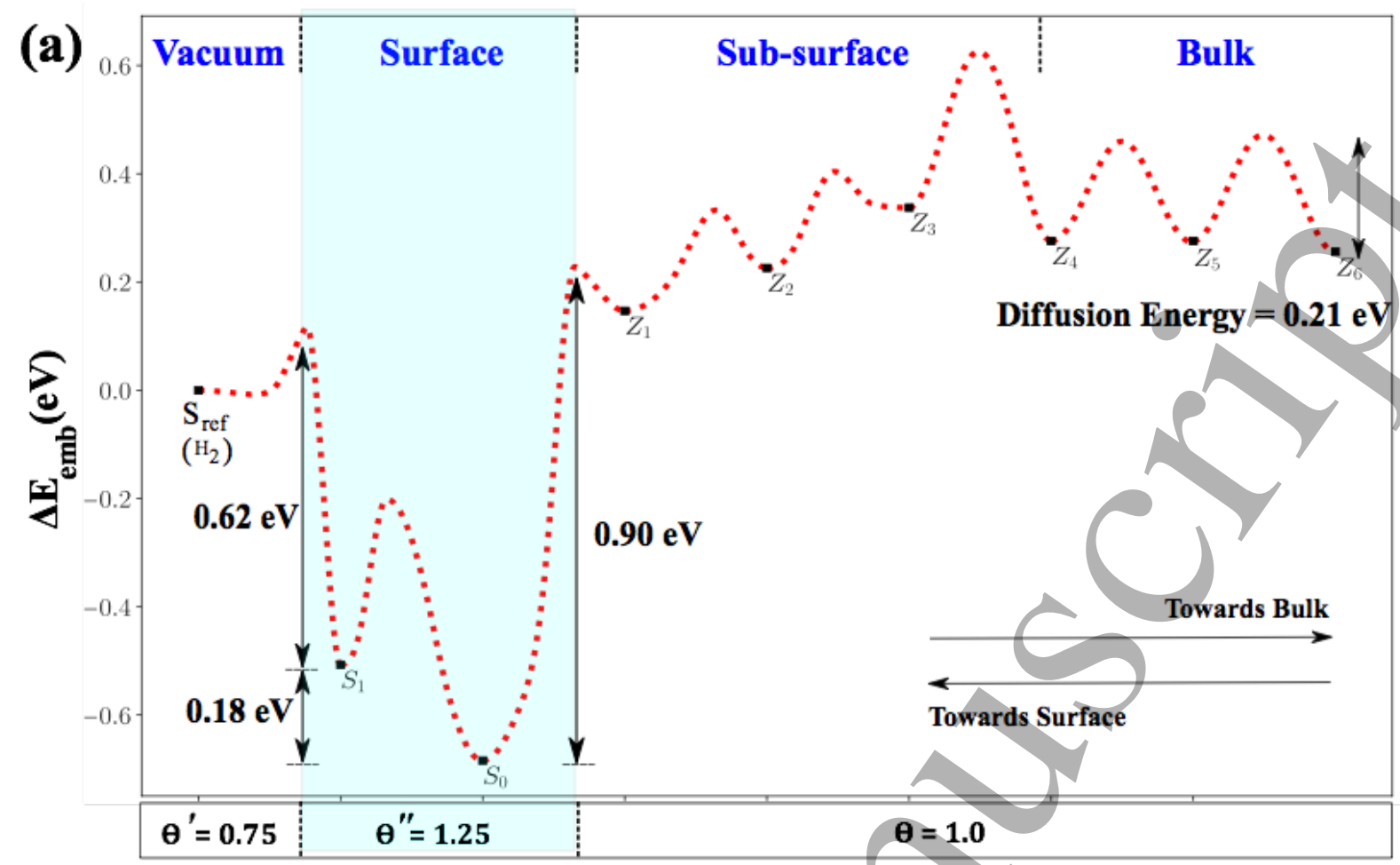

(b)

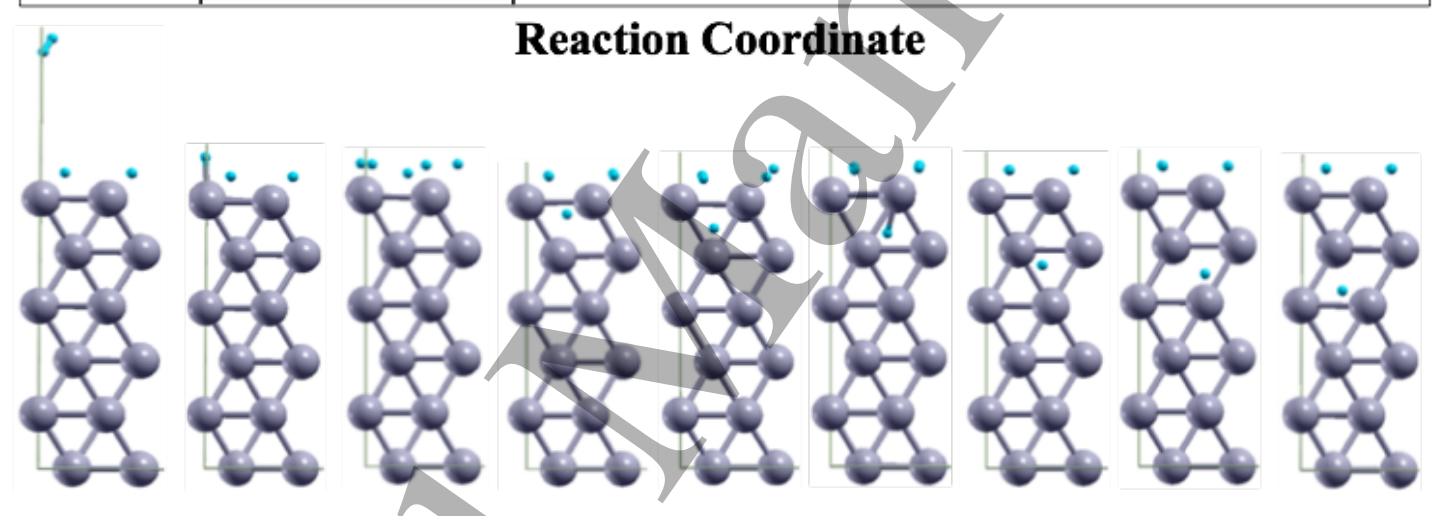

Figure 2: (a) embedding energy $\Delta E_{e m b}$ plotted versus the location of the hydrogen atom along the path leading from the bulk to vacuum at coverage $\boldsymbol{\Theta}=\mathbf{1 . 0}$ of the W(110) surface. (b) schematic cartoons of the stable $S_{\mathrm{i}}$ and $Z_{\mathrm{j}}$ positions along this path.

The energy profile exhibits four distinct regions:

(a) The bulk region extends from the bottom ( $Z_{6}$ and below) up to the $Z_{4}$ position around $3 \AA$ below the surface. It is characterized by an activation energy for diffusion between $E^{\ddagger}=0.19 \mathrm{eV}$ and $E^{\ddagger}=0.21 \mathrm{eV}$ (Table 2), in excellent agreement with the one determined into the bulk with no ZPE correction at $E^{\ddagger}=0.20 \mathrm{eV}[25,34]$ and $0.21 \mathrm{eV}$

[29]. The solution energy $\Delta E_{\text {sol }}$ is also in excellent agreement with the bulk properties: it is around $\Delta E_{\text {sol }}==0.85 \mathrm{eV}\left(\Delta E_{\text {sol }}^{Z P E}=0.98 \mathrm{eV}\right)$ (Table 1) and was previously 
determined at $\Delta E_{\text {sol }}=0.93 \mathrm{eV}\left(\Delta E_{\text {sol }}^{Z P E}=1.04\right) \mathrm{eV}$ in the bulk [25] using the same methodology.

(b) The sub-surface region extends over the $Z_{4}$ to $Z_{1}$ positions up to $0.5 \AA$ below the surface. It is characterized by barriers of diffusion in the range of $E^{\ddagger}=0.11 \mathrm{eV}$ to $E^{\ddagger}=$ $0.33 \mathrm{eV}$ (Table 2) scattered around the bulk value at $E^{\ddagger}=0.20 \mathrm{eV}$, while the solution energy remains in the same range as the one of the bulk at $\Delta E_{\text {sol }}=0.93 \mathrm{eV}$ (Table1); a slight increase in $\Delta E_{\text {sol }}$ is however observed up to $1.07 \mathrm{eV}$, in good agreement with a previous study led on the bare W(110) surface by Sun et al. [79] and Yang et al [80].

(c) The surface region characterizes itself by a solution energy that drops almost to zero (Table 1), which is consistent with the well-known tendency of $\mathrm{H}_{2}$ to dissociate on tungsten. In this region the unit-cell has a local coverage of $\Theta^{\prime \prime}=1.25$. The energy profile displays a diffusion step on the surface from $S_{1}$ to $S_{0}$. Then from $S_{0}$ a bond is formed with a hydrogen atom adsorbed on the surface (Figure 3b) leading to the formation of a $\mathrm{H}_{2}$ molecule. The activation energy for surface diffusion is $E_{\mathrm{S}_{0} \rightarrow \mathrm{S}_{1}}^{\ddagger}=$ $0.48 \mathrm{eV}$ and for recombination is $E_{\mathrm{S}_{1} \rightarrow \mathrm{S}_{\text {ref }}}^{\ddagger}=0.62 \mathrm{eV}$, the difference in energy between $\mathrm{S}_{0}$ and $\mathrm{S}_{1}$ being $0.18 \mathrm{eV}$. In the end, the overall barrier for desorption is $E_{\mathrm{S}_{0} \rightarrow \mathrm{S}_{\mathrm{ref}}}^{\ddagger}=$ $0.80 \mathrm{eV}$. In the backward direction, the absorption energy to jump back into the subsurface region is $E_{\mathrm{S}_{1} \rightarrow \mathrm{Z}_{1}}^{\ddagger}=0.90 \mathrm{eV}$.

(d) In the vacuum region, a hydrogen molecule is formed, and the surface is left with a local coverage of $\Theta^{\prime}=0.75$, which corresponds to the reference state with an embedding energy $\Delta E_{\text {emb }}$ is zero.

The details of the path from the $\mathrm{S}_{0}$ position up to the recombination in the gas phase are provided in the supplementary information. 
3.3 - Hydrogen desorption/absorption from the W(100) saturated surface (coverage $\Theta=2.0)$

Table 3 shows the embedding $\Delta E_{e m b}$ and solution $\Delta E_{s o l}$ energies of a hydrogen atom occupying the $Z_{1}-Z_{6} T_{d}$ sites below the hydrogen-saturated unit-cell at coverage $\Theta=2$. ZPE corrected energies are also displayed. Again, the main effect of the ZPE correction is to offset embedding and solution energy values by around 0.1 to $0.2 \mathrm{eV}$. As on the W(110) surface, two distinct configurations are observed and are labeled $\mathrm{S}_{0}$ and $\mathrm{S}_{1}$. In the $\mathrm{S}_{0}$ configuration, the geometry of the ad-layer corresponds to the stable configuration for a coverage of $\Theta^{\prime \prime}=2.25$ on the W(100) surface.

Table 3: Embedding and solution energies as defined in equation 1 and 2 . The $Z_{\mathrm{j}}$ refer to the location of the interstitial sites below the $\mathrm{W}(100)$. The distance from $\mathrm{Zj}$ to the surface is given by $\mathrm{d}_{\mathrm{H} \text {-surf. }}$

\begin{tabular}{cccccc}
\hline \hline $\mathrm{Z}_{\mathrm{j}}$ & $\Delta E_{\text {emb }}$ & $\Delta E_{\text {sol }}$ & $\Delta E_{\text {emb }}^{Z P E}$ & $\Delta E_{\text {sol }}^{Z P E}$ & $\mathrm{~d}_{\mathrm{H}-\mathrm{surf}}(\AA)$ \\
\hline$S_{\text {ref }}$ & 0.00 & 0.74 & 0.00 & 0.72 & +3.97 \\
$\mathrm{~S}_{1}$ & -0.63 & 0.12 & -0.46 & 0.20 & +1.73 \\
$\mathrm{~S}_{0}$ & -0.77 & -0.03 & -0.66 & 0.01 & +0.11 \\
$\mathrm{Z}_{1}$ & -0.43 & 0.31 & -0.22 & 0.43 & -0.80 \\
$\mathrm{Z}_{2}$ & -0.05 & 0.69 & 0.13 & 0.78 & -1.59 \\
$\mathrm{Z}_{3}$ & 0.00 & 0.74 & 0.22 & 0.87 & -2.42 \\
$\mathrm{Z}_{4}$ & 0.08 & 0.82 & 0.28 & 0.93 & -3.22 \\
$\mathrm{Z}_{5}$ & 0.08 & 0.82 & 0.27 & 0.93 & -3.99 \\
$\mathrm{Z}_{6}$ & 0.09 & 0.83 & 0.28 & 0.93 & -4.76 \\
\hline \hline
\end{tabular}

Figure 4 shows the full energy profile corresponding to the desorption mechanism of hydrogen atom from the saturated $\mathrm{W}(100)$ surface at coverage $\Theta=2.0$. The activation energies between $\mathrm{Z}_{\mathrm{j}}$ and $\mathrm{Z}_{\mathrm{j}-1}$ in $\mathrm{W}(100)$ are reported in Table 4 toward the surface $E_{\rightarrow \text { surf }}^{\ddagger}$ and toward the bulk 
$E_{\rightarrow \text { bulk }}^{\ddagger}$. They were taken from the NEB calculations and are not ZPE corrected. Here again, different paths could have been selected and for computational efficiency, we chose the shortest path connecting the minimal energy stationary states leading from the bulk to the surface.

Table 4: Activation energies toward the surface $E_{\rightarrow \text { surf }}^{\ddagger}$ and toward the bulk $E_{\rightarrow \text { bulk }}^{\ddagger}$ between $\mathrm{Z}_{\mathrm{j}}$ and $\mathrm{Z}_{\mathrm{j}-1}$ for the $\mathrm{W}(100)$ surface at coverage $\Theta=2.0$.

\begin{tabular}{ccc}
\hline \hline $\mathrm{Z}_{\mathrm{j}}-\mathrm{Z}_{\mathrm{j}+1}$ & $E_{\rightarrow \text { surf }}^{\ddagger}$ & $E_{\rightarrow \text { bulk }}^{\ddagger}$ \\
\hline $\mathrm{S}_{\mathrm{ref}}-\mathrm{S}_{1}$ & 0.64 & 0.03 \\
$\mathrm{~S}_{1}-\mathrm{S}_{0}$ & 0.37 & 0.23 \\
$\mathrm{~S}_{0}-\mathrm{Z}_{1}$ & 0.14 & 0.47 \\
$\mathrm{Z}_{1}-\mathrm{Z}_{2}$ & 0.05 & 0.42 \\
$\mathrm{Z}_{2}-\mathrm{Z}_{3}$ & 0.24 & 0.29 \\
$\mathrm{Z}_{3}-\mathrm{Z}_{4}$ & 0.16 & 0.24 \\
$\mathrm{Z}_{4}-\mathrm{Z}_{5}$ & 0.20 & 0.20 \\
$\mathrm{Z}_{5}-\mathrm{Z}_{6}$ & 0.20 & 0.20 \\
\hline \hline & & \\
& &
\end{tabular}




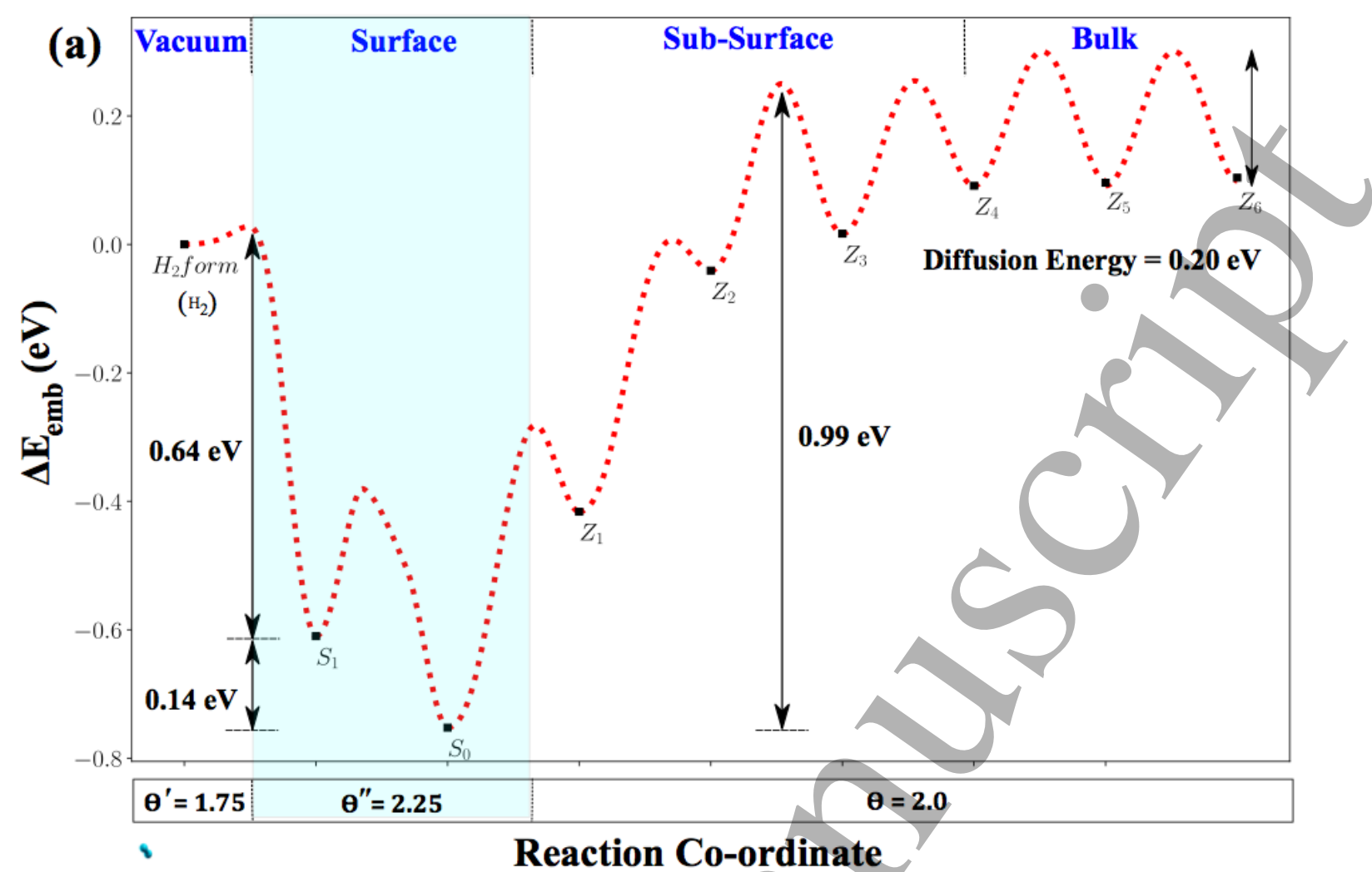

(b)

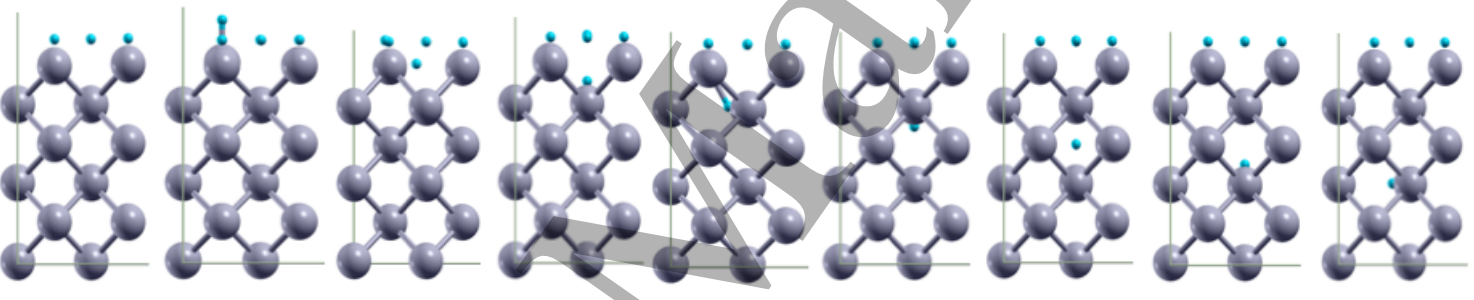

Figure 3: (a) Embedding energy $\Delta \boldsymbol{E}_{\text {emb }}$ plotted versus the location of the hydrogen atom along the path leading from the bulk to vacuum at coverage $\boldsymbol{\Theta}=\mathbf{2 . 0}$ of the W(100) surface. (b) schematic cartoons of the stable $S_{i}$ and $Z_{j}$ positions along this path.

Similar to the case of the saturated W(110) profile, the energy profile for the W(100) saturated surface also displays four distinct regions:

(a) The bulk region extends from the bottom ( $Z_{6}$ and below) up to the $Z_{4}$ position, around $3.2 \AA$ below the surface. The activation energy for diffusion is $E^{\ddagger}=0.20 \mathrm{eV}$ (Table 4) as in the bulk. The solution energy is at $\Delta E_{\text {sol }}=0.83 \mathrm{eV}\left(\Delta E_{\text {sol }}^{Z P E}=0.93 \mathrm{eV}\right)$ (Table 3) close to its bulk value at $\Delta E_{\text {sol }}=0.93 \mathrm{eV}\left(\Delta E_{\text {sol }}^{Z P E}=1.04\right) \mathrm{eV}$

(b) The sub-surface region extends over the $Z_{4}$ to $Z_{1}$ positions up to $0.8 \AA$ below the 
surface. The diffusion profile is again distorted, but the solution energy monotonously decreases to $\Delta E_{\text {sol }}=0.44 \mathrm{eV}$ (Table 3) when approaching the surface. This trend is comparable to the one below the bare W(100) surface [79].

(c) On the saturated surface, the solution energy drops to almost zero (Table 3), where the total local coverage of the unit-cell reaches $\Theta^{\prime \prime}=2.25$. The diffusion and recombination steps display activation energies of $E_{\mathrm{S}_{0} \rightarrow \mathrm{S}_{1}}^{\ddagger}=0.37 \mathrm{eV}$ and $E_{\mathrm{S}_{1} \rightarrow \mathrm{S}_{\mathrm{ref}}}^{\ddagger}=$ $0.64 \mathrm{eV}$ toward the surface, respectively. Combining both the diffusion and recombination step leads to an overall barrier for desorption of $E_{\mathrm{S}_{0} \rightarrow}^{\ddagger} \mathrm{S}_{\mathrm{ref}}=0.78 \mathrm{eV}$. In the opposite direction, the absorption mechanism to diffuse back into the sub-surface region is made of multiple steps involving energy barriers below $0.5 \mathrm{eV}$ given in Table 4. As discussed in the supplementary information, due to the strong asymmetry of these barriers, this multi-step process from $\mathrm{S}_{0}$ to $\mathrm{Z}_{3}$ can be approximated by a single step with an activation energy $E_{\mathrm{S}_{0} \rightarrow \mathrm{Z}_{3}}^{\ddagger}=0.99 \mathrm{eV}$ as shown in Figure 3a. The same approximation is used above from the $\mathrm{S}_{0}$ to $\mathrm{S}_{\mathrm{ref}}$ positions.

(d) In vacuum, a hydrogen molecule is formed, leaving the surface of the unit-cell with a local coverage of $\Theta^{\prime}=1.75$ and the embedding energy $\Delta E_{\text {emb }}$ at zero (reference state again).

The details of the path from the $\mathrm{S}_{0}$ position up to the recombination in the gas phase are provided in the supplementary information.

\section{Recombination and absorption mechanisms below saturation}

The coverage ratio of hydrogen on tungsten is known to decrease with increasing temperature up to the point where the bare surface of tungsten is recovered. The obvious consequence is that the desorption and reversely the absorption mechanisms are modified accordingly. Of 
course, we do not have here the computational capability to run NEB calculations at each coverage. Nevertheless, in order to determine the general trend that governs the evolution of the absorption/desorption mechanism with evolving coverages, we ran additional NEB calculations on selected coverages at $\Theta=0.75$ and $\Theta=0.50$ on the W(110) surface, and $\Theta=$ 0.50 on the $\mathrm{W}(100)$

\section{$0.75)$}

4.1 Hydrogen desorption/absorption mechanisms on $W(110)$ below saturation $(\Theta=$

Figure 4 shows the desorption and recombination mechanism of hydrogen on W(110) with $\Theta=0.75$ for the path we selected. The energy at $\mathrm{S}_{0}$ corresponds to the most stable $\Theta=0.75$ adsorption pattern. While other adsorption patterns are possible at coverage $\Theta=0.75$, such configurations have higher energy and their probability to exist would be negligible, as will be shown in a forthcoming publication. Again, we choose the shortest path connecting the minimal energy stationary states leading from the bulk to the surface.

The general trend of the energy profile shown in Figure 4 is the same as the one observed on the saturated surface at coverage $\Theta=1.0$ : the energy profile in the bulk and sub-surface regions behaves the same as before and the solution energy remains roughly around the bulk value. On the contrary, a drastic change appears on the surface: the activation energy for recombination leading to desorption rises dramatically from $E_{\mathrm{S}_{0} \rightarrow \mathrm{S}_{\mathrm{ref}}}^{\ddagger}=0.78 \mathrm{eV}$ at saturation to $E_{\mathrm{S}_{0} \rightarrow \mathrm{S}_{\text {ref }}}^{\ddagger}=$ $1.35 \mathrm{eV}$ at $\Theta=0.75$. The process for absorption into the bulk nearly doubles from $E_{\mathrm{S}_{0} \rightarrow \mathrm{z}_{1}}^{\ddagger}=$ $0.90 \mathrm{eV}$ at saturation to $E_{\mathrm{S}_{0} \rightarrow \mathrm{z}_{1}}^{\ddagger}=1.75 \mathrm{eV}$ at $\Theta=0.75$. The same was calculated at coverage $\Theta=0.5$ (not shown) for which the activation energies for recombination and absorption are $E_{S_{0} \rightarrow S_{r e f}}^{\ddagger}=1.42 \mathrm{eV}$ and $E_{\mathrm{S}_{1} \rightarrow \mathrm{z}_{1}}^{\ddagger}=1.72 \mathrm{eV}$, respectively. 


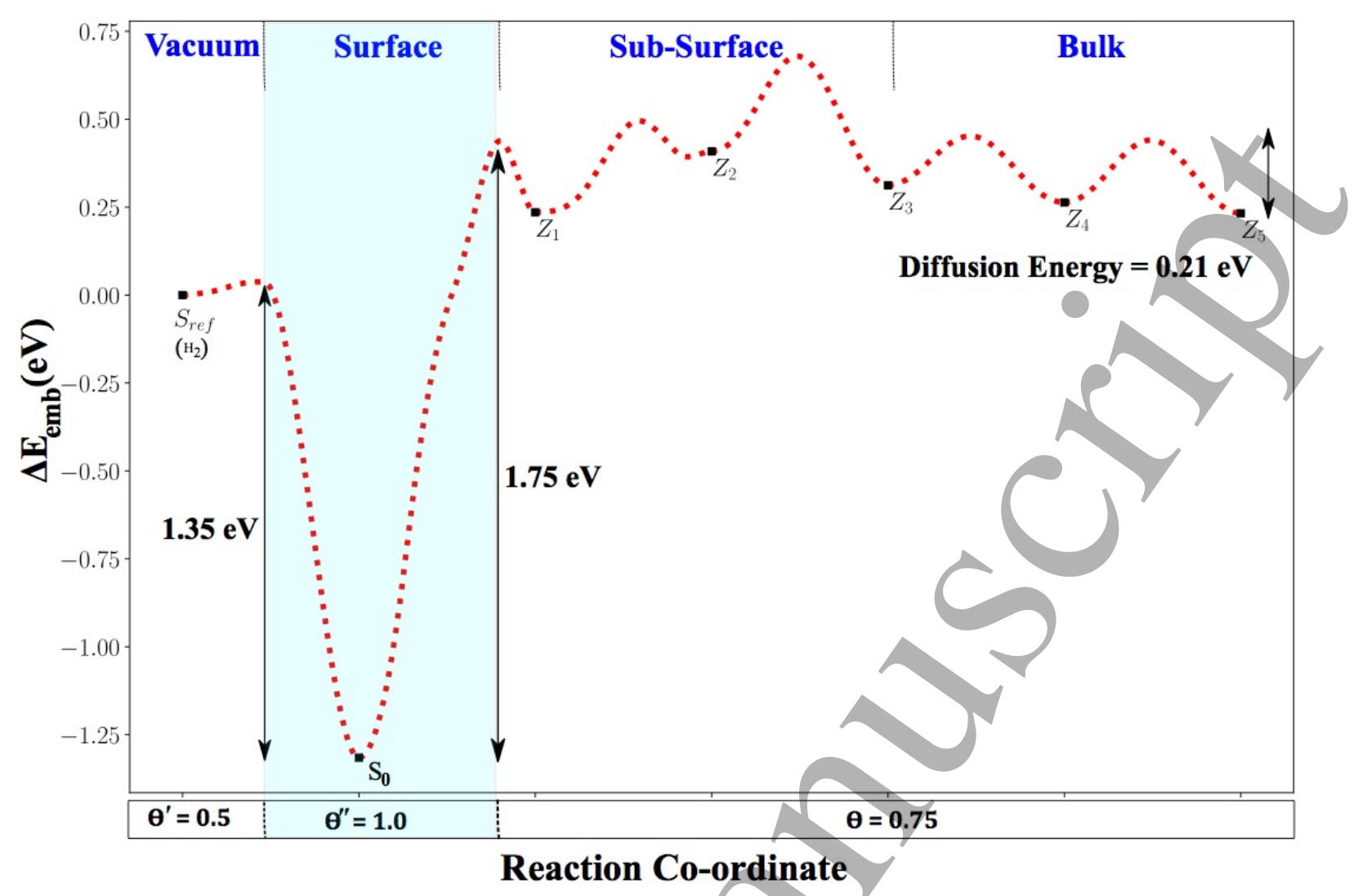

Figure 4: Embedding energy $\Delta \boldsymbol{E}_{\text {emb }}$ plotted versus the location of the hydrogen atom along the path leading from the bulk to vacuum at coverage $\boldsymbol{\Theta}=\mathbf{0 . 7 5}$ of the $\mathrm{W}(110)$ surface.

4.2 Hydrogen desorption/absorption mechanisms on W(100) below saturation $(\Theta=$

Figure 5 shows the desorption and recombination mechanism of a hydrogen atom from the bulk to the $W(100)$ surface at coverage $\Theta=0.5$. Here the question of choosing another path for the diffusion in the sub-surface, surfacing and recombination of hydrogen is more relevant. As shown by Yang et al.[80], and because the surface reconstructs at coverage $\Theta=0.5$, the tetrahedral sites below the surface are not equivalent and depend on their location relative to a short-bridge (SB) or a long-bridge (LB) site above. Nevertheless, the LB site is $0.45 \mathrm{eV}$ higher in energy than the SB sites, resulting in a higher activation barrier for recombination, making this process less likely to occur. Again, the shortest path connecting the minimal energy stationary states was selected. 
The overall nature of the diffusion process shown in Figure 5 is the same as the one calculated on the saturated surface in the bulk and sub-surface regions. On the contrary, in the surface region, the recombination step displays a significant increase in its activation energy which surges to $E_{\mathrm{S}_{0} \rightarrow \mathrm{S}_{\text {ref }}}^{\ddagger}=1.51 \mathrm{eV}$ from $E_{\mathrm{S}_{0} \rightarrow \mathrm{S}_{\text {ref }}}^{\ddagger}=0.78 \mathrm{eV}$ at saturation. The mechanism for absorption into the bulk region is also significantly altered: while it is still made of multiple steps which we approximate by a single one from $\mathrm{S}_{0}$ to $\mathrm{Z}_{3}$, the global activation barrier surges to $E_{\mathrm{S}_{0} \rightarrow \mathrm{Z}_{3}}^{\ddagger}=1.68 \mathrm{eV}$ from $E_{\mathrm{S}_{0} \rightarrow \mathrm{Z}_{3}}^{\ddagger}=0.99 \mathrm{eV}$ at saturation. The validity of the "single-step" approximation is here even more legitimate than at saturation, since we see the strongest asymmetry of the involved activation barriers. Some details of the path from $\mathrm{S}_{0}$ to $\mathrm{Z}_{3}$ are given in the supplementary information along with the related activation energies.

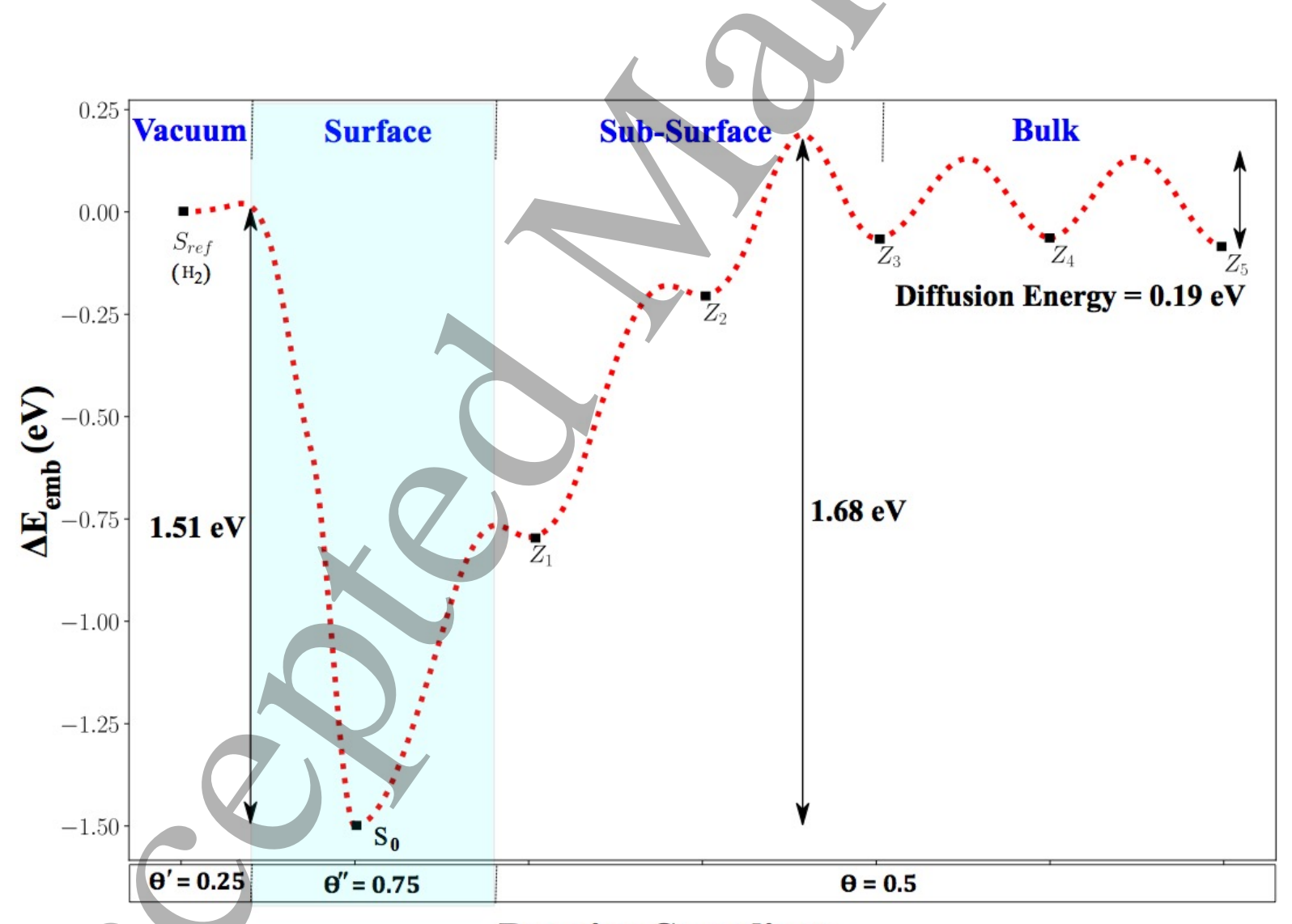

\section{Reaction Co-ordinate}

Figure 5: embedding energy $\Delta E_{\text {emb }}$ plotted versus the location of the hydrogen atom along the path leading from the bulk to vacuum at coverage $\Theta=0.50$ of the $\mathrm{W}(100)$ surface. 


\section{Discussion}

\section{1 - Surface effects: absorption and desorption of hydrogen in tungsten}

A common feature to all of the energy profiles presented in this work is the very small energy barrier $E_{\mathrm{S}_{\mathrm{ref}} \rightarrow \mathrm{S}_{0}}^{\ddagger}$ for the dissociation of a hydrogen molecule onto both the W(110) and W(100) surfaces. It never exceeds $0.11 \mathrm{eV}$ on the saturated $\mathrm{W}(110)$ surface and commonly lies around 0.01 to $0.04 \mathrm{eV}$. This means that in the reverse direction, the activation energy to recombine two hydrogen atoms on a surface with macroscopic coverage $\Theta$ is well approximated as $E_{\mathrm{S}_{0} \rightarrow \mathrm{S}_{\mathrm{ref}}}^{\ddagger} \approx-\Delta E_{e m b}$, with $\Delta E_{e m b}$ (eq. 2) taken at the $\mathrm{S}_{0}$ surface site with no ZPE consistently with the NEB profile. The same approximation $E_{\mathrm{S}_{0} \rightarrow \mathrm{S}_{\mathrm{ref}}}^{\ddagger} \approx-\Delta E_{e m b}$ was made by Markelj and al. [62]. Nevertheless, in order to confirm the validity of this approximation, we reported in Tables 5 and $\mathbf{6}$ the numerical values of $-\Delta E_{e m b}$ and the activation energies $E_{\mathrm{S}_{0} \rightarrow \mathrm{S}_{\text {ref }}}^{\ddagger}$ extracted directly from the minimum energy paths calculated via NEB for different coverages $\Theta$ of the $\mathrm{W}(110)$ and $\mathrm{W}(100)$ surfaces. The comparison shows that the total activation barrier from $E_{\mathrm{S}_{0} \rightarrow \mathrm{S}_{\text {ref }}}^{\ddagger}$ can be estimated with a very good approximation from $-\Delta E_{\text {emb }}$ taken at $\mathrm{S}_{0}$; this approximation allows us to extend the set of coverages for which $E_{\mathrm{S}_{0} \rightarrow \mathrm{S}_{\text {ref }}}^{\ddagger}$ can be estimated.

Tables 5 and $\mathbf{6}$ also provide the activation barrier for absorption into the bulk $E_{\mathrm{S}_{0} \rightarrow \text { bulk }}^{\ddagger}$ at each investigated coverage. For the $\mathrm{W}(110)$ surface, absorption is a one step process: it can be considered to take place between $\mathrm{S}_{0}$ and $\mathrm{Z}_{1}$, and the corresponding activation barrier is $E_{\mathrm{S}_{0} \rightarrow \mathrm{Z}_{1}}^{\ddagger}$. For the $\mathrm{W}(100)$ surface, absorption is the result of a multistep process: it can be considered to take place between $\mathrm{S}_{0}$ and $\mathrm{Z}_{3}$, with the corresponding activation barrier $E_{\mathrm{S}_{0} \rightarrow \mathrm{Z}_{3}}^{\ddagger}$. In order to adopt a unique notation, activation energies for hydrogen to penetrate below both surfaces are referred to as $E_{\mathrm{S}_{0} \rightarrow \text { bulk }}^{\ddagger}$ in Table 5 and 6 and throughout the rest of the paper. 
Table 5 : Approximated $\left(-\Delta E_{e m b}\right)$ and directly calculated values from NEBs $\left(E_{\mathrm{S}_{0} \rightarrow \mathrm{S}_{\text {ref }}}^{\ddagger}\right)$ of the activation barriers for recombination of two hydrogen atoms on the $\mathrm{W}(110)$ surface at different coverages $\Theta$. The activation energy for absorption into the bulk as defined into the text $E_{\mathrm{S}_{0} \rightarrow \text { bulk }}^{\neq}$ are also given for coverages at which NEB calculations were ran.

\begin{tabular}{llll}
\hline \hline & $\Theta$ & $-\Delta E_{\text {emb }} / E_{\mathrm{S}_{0} \rightarrow \mathrm{S}_{\text {ref }}}^{\ddagger}$ & $E_{\mathrm{S}_{0} \rightarrow \text { bulk }}^{\ddagger}$ \\
\hline \multirow{3}{*}{ Surface } & 0.50 & $1.44 / 1.41$ & 1.68 \\
& 0.75 & $1.33 / 1.35$ & 1.75 \\
& 1.00 & $0.69 / 0.80$ & 0.90 \\
\hline \hline
\end{tabular}

Table 6 : Approximated $\left(-\Delta E_{e m b}\right)$ and directly calculated values from NEBs $\left(E_{\mathrm{S}_{0} \rightarrow \mathrm{S}_{\text {ref }}}^{\ddagger}\right)$ of the activation barriers for recombination of two hydrogen atoms on the W(100) surface at different coverages $\Theta$. The activation energy for absorption into the bulk as defined into the text $E_{\mathrm{S}_{0} \rightarrow \text { bulk }}^{\ddagger}$ are also given for coverages at which NEB calculations were ran.

\begin{tabular}{|c|c|c|}
\hline & $\Delta E_{e m b} / E_{\mathrm{S}_{0} \rightarrow \mathrm{S}_{\mathrm{ref}}}^{\ddagger}$ & $E_{\mathrm{S}_{0} \rightarrow \text { bulk }}^{\ddagger}$ \\
\hline & $1.50 / 1.51$ & 1.68 \\
\hline & 1.31 & \\
\hline 1.00 & 1.47 & \\
\hline 1.25 & 1.40 & \\
\hline 1.50 & 1.38 & \\
\hline 1.75 & 1.47 & \\
\hline 2.00 & $0.77 / 0.78$ & 0.99 \\
\hline
\end{tabular}




\section{2 - Discussion with regard to experimental data and kinetic models}

In the following, we discuss to which extent surface phenomena can impact the shape of TPD spectra, considering the mechanisms of hydrogen recombination and desorption from tungsten. As no flux of atom impinges the surface during such experiment, we neglect desorption as the results of the recombination of a hydrogen atom in vacuum with a hydrogen atom of the surface following an Eley-Rideal or hot-atom mechanism. In tokamak, such recombination mechanisms have to be considered for detached regime of the plasma during which a high flux of neutrals impinges the surface.

\subsection{1 - Coverage dependent activation energies}

TPD spectra are recorded on single- and poly-crystalline samples and their shape are well fitted by rate-equation models incorporating different sets of activation energies. Guterl et al. [60] and Hodille et al. [52] used a set of six energies ranging from $0.85 \mathrm{eV}$ to $1.35 \mathrm{eV}$; these energies intend to mimic the multiple trapping that occurs in vacancies. Ogorodnikova et al. $[15,48]$, Schmid et al.[54,55] and Poon et al. [58] instead used two activation energies, modeling a low energy trap at around $0.9 \mathrm{eV}$ and a high energy trap around $1.4 \mathrm{eV}$.

Using the lower and upper limits of the energies as references $(0.9 \mathrm{eV}-1.4 \mathrm{eV})$, we compare the coverage dependent activation energies $E_{\mathrm{S}_{0} \rightarrow \mathrm{S}_{\text {ref }}}^{\ddagger}$ that we computed for the recombination step to frame their significance in terms of the energetics of processes relevant to modeling TPD experiments. At saturation we find the lowest activation energies for hydrogen recombination, they are $E_{\mathrm{S}_{0} \rightarrow \mathrm{S}_{\text {ref }}}^{\ddagger}=0.80 \mathrm{eV}$ and $E_{\mathrm{S}_{0} \rightarrow \mathrm{S}_{\mathrm{ref}}}^{\ddagger}=0.78 \mathrm{eV}$ for the $\mathrm{W}(110)$ and $\mathrm{W}(100)$, respectively; these values are lower than the activation energy for the low energy trap at 0.9 $\mathrm{eV}$. In contrast, below saturation, the activation energies for recombination are in the range of $E_{\mathrm{S}_{0} \rightarrow \mathrm{S}_{\mathrm{ref}}}^{\ddagger}=1.35 \mathrm{eV}$ to $E_{\mathrm{S}_{0} \rightarrow \mathrm{S}_{\mathrm{ref}}}^{\ddagger}=1.51 \mathrm{eV}$ depending on the coverage and orientation of the 
surface; this is close to the activation energy of the high energy traps at $1.4 \mathrm{eV}$.

A simple estimate of the temperature at peak maximum in a TPD experiment can be proposed based on the activation barriers we computed. Considering both first and second order kinetic laws for desorption, we solved the equations $\frac{d \theta}{d t}=\theta v_{0} \exp \left(-\frac{E_{\mathrm{S}_{0} \rightarrow \mathrm{S}_{\mathrm{ref}}}}{k_{B} T}\right)$ and $\frac{d \theta}{d t}=$ $\theta^{2} v_{0} \exp \left(-\frac{E_{\mathrm{S}_{0} \rightarrow \mathrm{S}_{\mathrm{ref}}}^{\ddagger}}{k_{B} T}\right)$ using a pre-exponential factor $v_{0}=10^{13} \mathrm{~s}^{-1}$ and a ramp in temperature $\beta=1 \mathrm{~K} \cdot \mathrm{s}^{-1}$. At saturation coverage, considering $\theta(t=0)=1$ and for $E_{\mathrm{S}_{0} \rightarrow \mathrm{S}_{\mathrm{ref}}}^{\ddagger}=0.80 \mathrm{eV}$, the temperature at peak maximum is $285 \mathrm{~K}$, independent of the order of the kinetics. Below saturation, considering a second order kinetic law, $\theta(t=0)=0.5-0.1$ and with activation barriers for desorption of $E_{\mathrm{S}_{0} \rightarrow \mathrm{S}_{\mathrm{ref}}}^{\ddagger}=1.35 \mathrm{eV}$ and $E_{\mathrm{S}_{0} \rightarrow \mathrm{S}_{\mathrm{ref}}}^{\ddagger}=1.51 \mathrm{eV}$, the temperatures at peak maximum are $475-495 \mathrm{~K}$ and $545-575 \mathrm{~K}$, respectively. Following a first order kinetic law, the temperature are $465 \mathrm{~K}$ and $535 \mathrm{~K}$ independently of the initial coverage $\theta(t=0)$. These raw estimates neglect many experimental parameters, but nevertheless provide an idea of the significance of surface mechanism on TPD spectra.

As a result, the effect of the surface on the desorption process of hydrogen from tungsten would be significant only below saturation, where the activation energy for recombination shifts from about $0.8 \mathrm{eV}$ at saturation to around $1.4 \mathrm{eV}$ below saturation. These values are partially consistent with experimental observations by Tamm and Schmidt $[22,83]$ who measured two activation barriers for the desorption of $\mathrm{H}$ on $\mathrm{W}$. They are $1.1 \mathrm{eV}$ and $1.4 \mathrm{eV}$ on the $\mathrm{W}(100)$ and $1.2 \mathrm{eV}$ and $1.5 \mathrm{eV}$ on the $\mathrm{W}(110)$ surface. Alnot et al. [71] found $E_{\mathrm{S}_{0} \rightarrow \mathrm{S}_{\mathrm{ref}}}^{\ddagger}=1.65 \mathrm{eV}$ below coverage $\Theta=0.5$ on the W(100) surface. Above $\Theta=0.5$, the same authors found activation barriers between $0.91 \mathrm{eV}$ and $1.35 \mathrm{eV}$ depending on the state of the adsorbate: stating that the 
value at $0.91 \mathrm{eV}$ would be for a delocalized or disorganized adsorbate while $1.35 \mathrm{eV}$ would be for a localized or organized adsorbate. Nahm and Gomer [70] also reported a decrease of the activation energy for $\mathrm{H}$ desorption from $\mathrm{W}(110)$ as a function of the coverage going from 1.43 $\mathrm{eV}$ at low coverages (below $\Theta=0.3$ ) to $1.26 \mathrm{eV}$ (at about $\Theta=0.8$ ).

To summarize, it is found in both present and experimental works that desorption energy decreases with the coverage. This agreement is qualitative and quantitative, particularly with the desorption energies derived the from experimental work from Alnot et al. [71].

\subsection{2 - Desorption and recombination mechanisms}

On the basis of the results of this work, the kinetic of hydrogen desorption from tungsten is briefly discussed based on two hypothetic limiting experimental conditions.

In the first one, the flux of hydrogen to the surface is low enough so that hydrogen does not accumulate below or at the surface. A local equilibrium between adsorbed hydrogen on the surface, the background gas and the bulk region is established. Below saturation of the surface, the activation barriers for desorption are comprised between $E_{\mathrm{S}_{0} \rightarrow \mathrm{S}_{\text {ref }}}^{\ddagger}=1.35 \mathrm{eV}$ and $E_{\mathrm{S}_{0} \rightarrow \mathrm{S}_{\mathrm{ref}}}^{\ddagger}=1.51 \mathrm{eV}$, indicating that desorption would be among the rate-limiting steps for hydrogen desorption. Following this hypothesis, a hydrogen atom from below the surface diffuses toward the surface at coverage $\theta$ and recombines with a hydrogen atom of the surface. After recombination, the surface is left with a local coverage $\theta^{\prime}$, before another hydrogen atom restore the coverage to its equilibrium value at $\theta$ as controlled by thermodynamics.

The second hypothesis assumes a larger flux of hydrogen from the bulk to the surface. Below saturation and because of the height of the barrier for desorption, hydrogen would accumulate below the surface leading to its saturation in an out-of-equilibrium state, which in turn would 
lower the barriers for desorption to $E_{\mathrm{S}_{0} \rightarrow \mathrm{S}_{\text {ref }}}^{\ddagger}=0.78 \mathrm{eV}$ and $E_{\mathrm{S}_{0} \rightarrow \mathrm{S}_{\text {ref }}}^{\ddagger}=0.80 \mathrm{eV}$. Following this assumption, the impact of the surface on the kinetics of desorption would be diminished.

Investigating the whole complexity of the kinetics of hydrogen desorption from tungsten is not the purpose of the present work, given the fact it depends on many factors like the temperature, the density profile of hydrogen, the bulk concentration, etc. We nevertheless herein provided the necessary DFT data that will allow further Macroscopic Rate-Equation (MRE) and Kinetic Monte-Carlo (KMC) simulations to tackle this issue.

\subsection{3 - Absorption into the bulk}

Here again more extended MRE and KMC making use of the present data will be necessary; we nevertheless briefly discussed the kinetic of absorption based on the present results. The global trend presented here is that the activation energy for absorption increases as the coverage decreases, with an increase of $E_{\mathrm{S}_{0} \rightarrow \text { bulk }}^{\ddagger}$ from below $1 \mathrm{eV}$ at saturation to $E_{\mathrm{S}_{0} \rightarrow \text { bulk }}^{\ddagger} \approx 1.7 \mathrm{eV}$ below saturation. In rate-equation modelling, such an increase is particularly important to consider when simulating low energy atomic or $\mathrm{H}_{2}$ gas exposure. Indeed, during such exposure, the concentration of hydrogen in tetrahedral sites, and thus in all defects, is highly dependent on the absorption process from the surface to the bulk [50]. An increase of the activation energy for this process would imply a much lower concentration of hydrogen in tetrahedral sites and thus a much lower overall retention and a much smaller migration depth.

\section{Conclusion}

In this work, we investigated the mechanisms for recombination/desorption and absorption of hydrogen from the $\mathrm{W}(100)$ and $\mathrm{W}(110)$ surfaces. The main results regarding the desorption 
mechanisms are:

a) At saturation, the desorption of a $\mathrm{H}_{2}$ molecule from the $\mathrm{W}(110)$ and $\mathrm{W}(100)$ surfaces implies a total activation barrier of $E_{\mathrm{S}_{0} \rightarrow \mathrm{S}_{\mathrm{ref}}}^{\ddagger}=0.78 \mathrm{eV}$ and $0.80 \mathrm{eV}$, respectively. This is below the activation energy from many traps in tungsten.

b) Below saturation, these activation barrier rises up to $E_{\mathrm{S}_{0} \rightarrow \mathrm{S}_{\mathrm{ref}}}^{\ddagger}=1.35 \mathrm{eV}$ to $1.51 \mathrm{eV}$ depending on the coverage and on the orientation of the surface, making of the surface a significant trap.

c) We further assumed two hypothetical experimental conditions in order to briefly discuss the kinetic of desorption of hydrogen from tungsten. At low hydrogen flux from the bulk to the surface and below saturation, the recombination mechanisms would be among the rate limiting steps for hydrogen desorption. At saturation, the impact of the surface would be much smaller. Considering larger fluxes of hydrogen from the bulk, the surface would remain at or close to saturation even in experimental conditions where such a coverage is not expected from a thermodynamic point of view. In this case, the impact on the kinetics will only be resolved by further rate-equation modellings.

Regarding the absorption of hydrogen into the bulk, we found that the activation barrier is only significant below saturation at around $1.7 \mathrm{eV}$ on both surfaces. This would imply a much lower concentration of hydrogen in tetrahedral sites and thus a much lower overall retention and a much smaller migration depth. 


\section{Acknowledgements}

This work has been carried out within the framework of the French Federation for Magnetic Fusion Studies (FR-FCM) and of the Eurofusion consortium, and has received funding from the Euratom research and training program 2014-2018 and 2019-2020 under grant agreement No 633053. This work also received fund within the framework of the A*MIDEX project (Grant No. ANR- 11-IDEX-0001-02) funded by the Investissements d'Avenir French Government program, managed by the French National Research agency. The views and opinions expressed herein do not necessarily reflect those of the European Commission. The authors of this paper were granted access to the high-performance computing resources of IDRIS and CINES under Allocation No. A0040806612 made by Grand Equipement National de Calcul Intensif and to the Marconi Supercomputer at CINECA Super Computing Application and Innovation Department, Bologna, Italy.

\section{Bibliography}

[1] Editors I P B, Chairs I P E G, Co-Chairs, Team I J C and Unit P I 1999 Chapter 1: Overview and summary Nucl. Fusion 392137

[2] Causey R, Wilson K, Venhaus T and R. Wampler W 1999 Tritium retention in tungsten exposed to intense fluxes of $100 \mathrm{eV}$ tritons Journal of Nuclear Materials 266-269 46771

[3] Rieth M, Dudarev SL, Gonzalez de Vicente S M, Aktaa J, Ahlgren T, Antusch S, Armstrong D E J, Balden M, Baluc N, Barthe M-F, Basuki W W, Battabyal M, Becquart C S, Blagoeva D, Boldyryeva H, Brinkmann J, Celino M, Ciupinski L, Correia J B, De Backer A, Domain C, Gaganidze E, García-Rosales C, Gibson J, Gilbert M R, Giusepponi S, Gludovatz B, Greuner H, Heinola K, Höschen T, Hoffmann A, Holstein N, Koch F, Krauss W, Li H, Lindig S, Linke J, Linsmeier Ch, López-Ruiz P, Maier H, Matejicek J, Mishra T P, Muhammed M, Muñoz A, Muzyk M, Nordlund K, Nguyen-Manh D, Opschoor J, Ordás N, Palacios T, Pintsuk G, Pippan R, Reiser J, Riesch J, Roberts S G, Romaner L, Rosiński M, Sanchez M, Schulmeyer W, Traxler H, Ureña A, van der Laan J G, Veleva L, Wahlberg S, Walter M, Weber T, Weitkamp T, Wurster S, Yar M A, You J H and Zivelonghi A 2013 Recent progress in research on tungsten materials for nuclear fusion applications in Europe Journal of Nuclear Materials 432 482-500 
[4] Philipps V 2011 Tungsten as material for plasma-facing components in fusion devices Journal of Nuclear Materials 415 S2-9

[5] Matthews G F, Beurskens M, Brezinsek S, Groth M, Joffrin E, Loving A, Kear M, Mayoral M-L, Neu R, Prior P, V Riccardo, Rimini F, Rubel M, Sips G, Villedieu E, Vries P de, Watkins M L and contributors E-J 2011 JET ITER-like wall-overview and experimental programme Phys. Scr. 2011014001

[6] Philipps V, Mertens Ph, Matthews G F and Maier H 2010 Overview of the JET ITER-like Wall Project Fusion Engineering and Design 85 1581-6

[7] Bucalossi J, Missirlian M, Moreau P, Samaille F, Tsitrone E, van Houtte D, BatalT, Bourdelle C, Chantant M, Corre Y, Courtois X, Delpech L, Doceul L, Douai D, Dougnac H, Faïsse F, Fenzi C, Ferlay F, Firdaouss M, Gargiulo L, Garin P, Gil C, Grosman A, Guilhem D, Gunn J, Hernandez C, Keller D, Larroque S, Leroux F, Lipa M, Lotte P, Martinez A, Meyer O, Micolon F, Mollard P, Nardon E, Nouailletas R, Pilia A, Richou M, Salasca S and Travère J-M 2014 The WEST project: Testing ITER divertor high heat flux component technology in a steady state tokamak environment Fusion Engineering and Design 89 907-12

[8] Loarte A, Lipschultz B, Kukushkin A S, Matthews G F, Stangeby P C, Asakura N, Counsell G F, G. Federici, Kallenbach A, Krieger K, Mahdavi A, Philipps V, Reiter D, Roth J, Strachan J, Whyte D, R. Doerner, Eich T, Fundamenski W, Herrmann A, Fenstermacher $M$, Ghendrih $P$, Groth $M$, Kirschner $A$, S. Konoshima, LaBombard B, Lang $P$, Leonard $A$ W, Monier-Garbet P, Neu R, Pacher H, Pegourie B, R.A. Pitts, Takamura S, Terry J, Tsitrone E, Layer the I S and Group D P T 2007 Chapter 4: Power and particle control Nucl. Fusion 47 S203

[9] Brezinsek S, Coenen J W, Schwarz-Selinger T, Schmid K, Kirschner A, Hakola A, Tabares F $L$, Meiden H J van der, Mayoral M-L, Reinhart M, Tsitrone E, Ahlgren T, Aints M, Airila M, Almaviva S, E. Alves, Angot T, Anita V, Parra R A, Aumayr F, Balden M, Bauer J, Yaala M B, Berger B M, R. Bisson, Björkas C, Radovic I B, Borodin D, Bucalossi J, Butikova J, Butoi B, Čadež I, R. Caniello, Caneve L, Cartry G, Catarino N, Čekada M, Ciraolo G, Ciupinski L, Colao F, Corre Y, C. Costin, Craciunescu T, Cremona A, Angeli M D, Castro A de, Dejarnac R, Dellasega D, Dinca P, T. Dittmar, Dobrea C, Hansen P, Drenik A, Eich T, Elgeti S, Falie D, Fedorczak N, Ferro Y, Fornal T, E. Fortuna-Zalesna, Gao L, Gasior P, Gherendi M, Ghezzi F, Gosar Ž, Greuner H, Grigore E, Grisolia C, M. Groth, Gruca M, Grzonka J, Gunn J P, Hassouni K, Heinola K, Höschen T, Huber S, Jacob W, Jepu I, X. Jiang, Jogi I, Kaiser A, Karhunen J, Kelemen M, Köppen M, Koslowski H R, Kreter A, Kubkowska M, M. Laan, Laguardia L, Lahtinen A, Lasa A, Lazic V, Lemahieu N, Likonen J, Linke J, Litnovsky A, Ch. Linsmeier, Loewenhoff T, et al 2017 Plasma-wall interaction studies within the EUROfusion consortium: progress on plasma-facing components development and qualification Nucl. Fusion 57116041

[10] Grisolia C 1999 Plasma wall interaction during long pulse operation in Tore Supra Journal of Nuclear Materials 266-269 146-52 
[11] G. Martin for T-S T 2003 Overview of steady-state operation on the Tore-Supra tokamak Nucl. Fusion 43 817-821

[12] Bisson R, Markelj S, Mourey O, Ghiorghiu F, Achkasov K, Layet J-M, Roubin P, Cartry G, Grisolia C and Angot T 2015 Dynamic fuel retention in tokamak wall materials: An in situ laboratory study of deuterium release from polycrystalline tungsten at room temperature Journal of Nuclear Materials 467 432-8

[13] Wang P, Jacob W, Gao L, Dürbeck T and Schwarz-Selinger T 2013 Comparing deuterium retention in tungsten films measured by temperature programmed desorption and nuclear reaction analysis Nuclear Instruments and Methods in Physics Research Section B: Beam Interactions with Materials and Atoms 300 54-61

[14] Roszell J P, Davis J W and Haasz A A 2012 Temperature dependence of deuterium retention mechanisms in tungsten Journal of Nuclear Materials 429 48-54

[15] Ogorodnikova O V, Roth J and Mayer M 2003 Deuterium retention in tungsten in dependence of the surface conditions Journal of Nuclear Materials 313-316 469-77

[16] Wang P, Jacob W, Gao L, Dürbeck T and Schwarz-Selinger T 2013 Comparing deuterium retention in tungsten films measured by temperature programmed desorption and nuclear reaction analysis Nuclear Instruments and Methods in Physics Research Section B: Beam Interactions with Materials and Atoms 300 54-61

[17] Mayer M, Gauthier E, Sugiyama K and von Toussaint U 2009 Quantitative depth profiling of deuterium up to very large depths Nuclear Instruments and Methods in Physics Research Section B: Beam Interactions with Materials and Atoms 267 506-12

[18] Alimov V Kh, Mayer M and Roth J 2005 Differential cross-section of the $D(3 \mathrm{He}, \mathrm{p}) 4 \mathrm{He}$ nuclear reaction and depth profiling of deuterium up to large depths Nuclear Instruments and Methods in Physics Research Section B: Beam Interactions with Materials and Atoms 234 169-75

[19] Markelj S, Ogorodnikova O V, Pelicon P, Selinger T S, Vavpetič P and Čadež I 2014 In situ nuclear reaction analysis of $D$ retention in undamaged and self-damaged tungsten under atomic D exposure Phys. Scr. 2014014047

[20] Poon M, Haasz A A, Davis J W and Macaulay-Newcombe R G 2003 Impurity effects and temperature dependence of $D$ retention in single crystal tungsten Journal of Nuclear Materials 313 199-203

[21] Markelj S, Čadež I, Pelicon P and Rupnik Z 2007 Studying processes of hydrogen interaction with metallic surfaces in situ and in real-time by ERDA Nuclear Instruments and Methods in Physics Research Section B: Beam Interactions with Materials and Atoms 259 989-96

[22] Kolasinski R D, Bartelt N C, Whaley J A and Felter T E 2012 Channeling of low-energy ions on hydrogen-covered single-crystal surfaces Phys. Rev. B 85115422 
[23] Kolasinski R D 2015 Analysis of hydrogen adsorption and surface binding configuration on tungsten using direct recoil spectrometry Journal of Nuclear Materials 463 1053-6

[24] Piazza Z A, Ajmalghan M, Ferro Y and Kolasinski R D 2018 Saturation of tungsten surfaces with hydrogen: A density functional theory study complemented by low energy ion scattering and direct recoil spectroscopy data Acta Materialia 145 388-98

[25] Fernandez N, Ferro $Y$ and Kato D 2015 Hydrogen diffusion and vacancies formation in tungsten: Density Functional Theory calculations and statistical models Acta Materialia 94 307-18

[26] Hodille E A, Fernandez N, Piazza Z A, Ajmalghan M and Ferro Y 2018 Hydrogen supersaturated layers in H/D plasma-loaded tungsten: A global model based on thermodynamics, kinetics and density functional theory data Physical Review Materials 2

[27] Moitra A and Solanki K 2011 Adsorption and penetration of hydrogen in W: A first principles study Computational Materials Science 50 2291-4

[28] Johnson D F and Carter E A 2010 Hydrogen in tungsten: Absorption, diffusion, vacancy trapping, and decohesion Journal of Materials Research 25 315-27

[29] Heinola K and Ahlgren T 2010 Diffusion of hydrogen in bcc tungsten studied with first principle calculations Journal of Applied Physics 107113531

[30] Heinola K and Ahlgren T 2010 First-principles study of $\mathrm{H}$ on the reconstructed W(100) surface Phys. Rev. B 81073409

[31] Heinola K, Djurabekova F and Ahlgren T 2018 On the stability and mobility of divacancies in tungsten Nuclear Fusion 58026004

[32] Nojima A and Yamashita K 2007 A theoretical study of hydrogen adsorption and diffusion on a W(1 110$)$ surface Surface Science 601 3003-11

[33] Nguyen-Manh D, Horsfield A P and Dudarev S L 2006 Self-interstitial atom defects in bcc transition metals: Group-specific trends Physical Review B $\mathbf{7 3}$

[34] Liu Y-L, Zhang Y, Zhou H-B, Lu G-H, Liu F and Luo G-N 2009 Vacancy trapping mechanism for hydrogen bubble formation in metal Physical Review B 79

[35] Sun Y, Peng Q and Lu G 2013 Quantum mechanical modeling of hydrogen assisted cracking in aluminum Physical Review $B \mathbf{8 8}$

[36] Lu G-H, Zhou H-B and Becquart C S 2014 A review of modelling and simulation of hydrogen behaviour in tungsten at different scales Nucl. Fusion $\mathbf{5 4} 086001$

[37] Yang L, Bergstrom Z J and Wirth B D 2018 Effect of interatomic potential on the energetics of hydrogen and helium-vacancy complexes in bulk, or near surfaces of tungsten Journal of Nuclear Materials 512 357-70 
[38] Sun L, Liu Y-N, Xiao W and Zhou M 2018 Hydrogen behaviors at the near-surface region of tungsten: A first-principles study Materials Today Communications 17 511-6

[39] Henriksson K O E, Vörtler K, Dreißigacker S, Nordlund K and Keinonen J 2006 Sticking of atomic hydrogen on the tungsten (001) surface Surface Science 600 3167-74

[40] Guterl J, Smirnov R D, Krasheninnikov S I, Uberuaga B, Voter A F and Perez D 2015 Modeling of hydrogen desorption from tungsten surface Journal of Nuclear Materials $463263-7$

[41] Maya P N 2016 Molecular dynamics studies of sticking and reflection of low-energy deuterium on single crystal tungsten Journal of Nuclear Materials 480 411-9

[42] Ogorodnikova O V, Markelj S and von Toussaint U 2016 Interaction of atomic and lowenergy deuterium with tungsten pre-irradiated with self-ions Journal of Applied Physics 119054901

[43] Fu B, Qiu M, Cui J, Li M and Hou Q 2018 The trapping and dissociation process of hydrogen in tungsten vacancy: A molecular dynamics study Journal of Nuclear Materials 508 278-85

[44] Oda T, Zhu D and Watanabe Y 2015 Kinetic Monte Carlo simulation on influence of vacancy on hydrogen diffusivity in tungsten Journal of Nuclear Materials 467 439-47

[45] Valles G, Panizo-Laiz M, González C, Martin-Bragado I, González-Arrabal R, Gordillo N, Iglesias R, Guerrero C L, Perlado J M and Rivera A 2017 Influence of grain boundaries on the radiation-induced defects and hydrogen in nanostructured and coarse-grained tungsten Acta Materialia Complete 277-86

[46] von Toussaint U, Schwarz-Selinger T and Schmid K 2015 First-passage kinetic Monte Carlo on lattices: Hydrogen transport in lattices with traps Journal of Nuclear Materials 463 1075-9

[47] Dumont F, Picaud F, Ramseyer C, Girardet C, Ferro Y and Allouche A 2008 Model for thermal desorption of hydrogen atoms from a graphite surface based on kinetic Monte Carlo simulations Phys. Rev. B 77233401

[48] Ogorodnikova O V, Roth J and Mayer M 2008 Ion-driven deuterium retention in tungsten Journal of Applied Physics 103034902

[49] Hodille E A, Bonnin X, Bisson R, Angot T, Becquart C S, Layet J M and Grisolia C 2015 Macroscopic rate equation modeling of trapping/detrapping of hydrogen isotopes in tungsten materials Journal of Nuclear Materials 467 424-31

[50] Hodille E A, Založnik A, Markelj S, Schwarz-Selinger T, Becquart C S, Bisson R and Grisolia C 2017 Simulations of atomic deuterium exposure in self-damaged tungsten Nucl. Fusion 57056002

[51] Hodille E A, Ghiorghiu F, Addab Y, Založnik A, Minissale M, Piazza Z, Martin C, Angot T, L. Gallais, Barthe M-F, Becquart C S, Markelj S, Mougenot J, Grisolia C and Bisson R 
2017 Retention and release of hydrogen isotopes in tungsten plasma-facing components: the role of grain boundaries and the native oxide layer from a joint experiment-simulation integrated approach Nucl. Fusion $\mathbf{5 7} 076019$

[52] Hodille E A, Ferro Y, Fernandez N, Becquart C S, Angot T, Layet J M, Bisson R and Grisolia C 2016 Study of hydrogen isotopes behavior in tungsten by a multi trapping macroscopic rate equation model Phys. Scr. 2016014011

[53] Ahlgren T, Heinola K, Vörtler K and Keinonen J 2012 Simulation of irradiation induced deuterium trapping in tungsten Journal of Nuclear Materials 427 152-61

[54] Schmid K, Rieger V and Manhard A 2012 Comparison of hydrogen retention in W and W/Ta alloys Journal of Nuclear Materials 426 247-53

[55] Schmid K, von Toussaint U and Schwarz-Selinger T 2014 Transport of hydrogen in metals with occupancy dependent trap energies Journal of Applied Physics 116134901

[56] Schmid K, Bauer J, Schwarz-Selinger T, Markelj S, Toussaint U V, Manhard A and Jacob W 2017 Recent progress in the understanding of $\mathrm{H}$ transport and trapping in W Phys. Scr. 2017014037

[57] Založnik A, Markelj S, Schwarz-Selinger T and Schmid K 2017 Deuterium atom loading of self-damaged tungsten at different sample temperatures Journal of Nuclear Materials 496 1-8

[58] Poon M, Haasz A A and Davis J W 2008 Modelling deuterium release during thermal desorption of D+-irradiated tungsten Journal of Nuclear Materials 374 390-402

[59] Benannoune S, Charles Y, Mougenot J and Gaspérini M 2018 Numerical simulation of the transient hydrogen trapping process using an analytical approximation of the McNabb and Foster equation International Journal of Hydrogen Energy 43 9083-93

[60] Guterl J, Smirnov R D, Krasheninnikov S I, Zibrov M and Pisarev A A 2015 Theoretical analysis of deuterium retention in tungsten plasma-facing components induced by various traps via thermal desorption spectroscopy Nucl. Fusion $\mathbf{5 5} 093017$

[61] Causey R A 2002 Hydrogen isotope retention and recycling in fusion reactor plasmafacing components Journal of Nuclear Materials 300 91-117

[62] Markelj S, Ogorodnikova O V, Pelicon P, Schwarz-Selinger T and Čadež I 2013 Temperature dependence of $D$ atom adsorption on polycrystalline tungsten Applied Surface Science $282478-86$

[63] 't Hoen M H J, Mayer M, Kleyn A W and Zeijlmans van Emmichoven P A 2013 Strongly Reduced Penetration of Atomic Deuterium in Radiation-Damaged Tungsten Phys. Rev. Lett. 111225001

[64] Sang C, Wang Z, Wang L, Ding R, Wang Q, Sun J and Wang D 2018 Modeling of fuel retention in the upper tungsten divertor of EAST from attached to detached divertor plasma Fusion Engineering and Design 136 908-13 
[65] Matveev D, Wensing M, Ferry L, Virot F, Barrachin M, Ferro Y and Linsmeier Ch 2018 Reaction-diffusion modeling of hydrogen transport and surface effects in application to single-crystalline Be Nuclear Instruments and Methods in Physics Research Section B: Beam Interactions with Materials and Atoms 430 23-30

[66] Pick M A and Sonnenberg K 1985 A model for atomic hydrogen-metal interactions application to recycling, recombination and permeation Journal of Nuclear Materials $131208-20$

[67] Pick M A, Davenport J W, Strongin M and Dienes G J 1979 Enhancement of Hydrogen Uptake Rates for Nb and Ta by Thin Surface Overlayers Physical Review Letters 43286 9

[68] Tamm P W and Schmidt L D 1971 Binding States of Hydrogen on Tungsten The Journal of Chemical Physics 54 4775-87

[69] Tamm P W and Schmidt L D 1969 Interaction of H2 with (100) W. 1. Binding States J. Chem. Phys. 51 5352-63

[70] Nahm T-U and Gomer R 1997 Desorption of H2 from W(110) and Fe covered W(110) surfaces Surface Science 380 434-43

[71] Alnot P, Cassuto A and King D A 1989 Adsorption and desorption kinetics with no precursor trapping: Hydrogen and deuterium on W \{100\} Surface Science 215 29-46

[72] Giannozzi P, Baroni S, Bonini N, Calandra M, Car R, Cavazzoni C, Davide Ceresoli, Chiarotti G L, Cococcioni M, Dabo I, Corso A D, Gironcoli S de, Fabris S, Fratesi G, Gebauer R, Gerstmann U, Gougoussis C, Anton Kokalj, Lazzeri M, Martin-Samos L, Marzari N, Mauri F, Mazzarello R, Stefano Paolini, Pasquarello A, Paulatto L, Sbraccia C, Scandolo S, Sclauzero G, Seitsonen A P, Smogunov A, Umari P and Wentzcovitch R M 2009 QUANTUM ESPRESSO: a modular and open-source software project for quantum simulations of materials J. Phys.: Condens. Matter 21395502

[73] Perdew J P, Burke K and Ernzerhof M 1996 Generalized Gradient Approximation Made Simple Phys. Rev. Lett. 77 3865-8

[74] Vanderbilt D 1990 Soft self-consistent pseudopotentials in a generalized eigenvalue formalism Phys. Rev. B 41 7892-5

[75] Marzari N, Vanderbilt D, De Vita A and Payne M C 1999 Thermal Contraction and Disordering of the Al(110) Surface Phys. Rev. Lett. 82 3296-9

[76] Baroni S, de Gironcoli S, Dal Corso A and Giannozzi P 2001 Phonons and related crystal properties from density-functional perturbation theory Rev. Mod. Phys. 73 515-62

[77] EW, Ren W and Vanden-Eijnden E 2002 String method for the study of rare events Phys. Rev. B 66052301 
[78] Kanai Y, Tilocca A, Selloni A and Car R 2004 First-principles string molecular dynamics: An efficient approach for finding chemical reaction pathways The Journal of Chemical Physics 121 3359-67

[79] Sun L, Jin S, Lu G-H and Wang L 2016 High hydrogen retention in the sub-surfaces of tungsten plasma facing materials: A theoretical insight Scripta Materialia Complete 147

[80] Yang L and Wirth B D 2019 First-principles study of hydrogen diffusion and selfclustering below tungsten surfaces Journal of Applied Physics 125165105 